\title{
CEREBROPLACENTAL DOPPLER RATIO IN EVALUATION OF SMALL FOR GESTATIONAL AGE AND PREDICTION OF ADVERSE PERINATAL OUTCOME
}

Desai Sanjay D', Jyotsna A. Deshmukh²

${ }^{1}$ Associate Professor, Department of Radiology, RCSM Govt. Medical College, Kolhapur, Maharashtra.

${ }^{2}$ Associate Professor, Department of Obstetrics \& Gynaecology, RCSM Govt. Medical College, Kolhapur, Maharashtra.

\section{ABSTRACT}

Small for gestational age fetuses often shows adverse perinatal outcome. In this study evaluated the clinically suspected cases of small for gestation age and adverse perinatal outcome by pusatility indices of umbilical, fetal middle cerebral artery and cerebroplacental doppler ratio.

\section{MATERIAL AND METHODS}

The study population is of 80 pregnancies of 30-41 weeks' gestation had diagnosed clinically as small for date over a period of one year. The UA PI, MCA PI and cerebroplacental doppler ratio were calculated.

\section{RESULTS}

Of the 80 pregnancies in the study 28 showed abnormal UA PI. Among these 20(71.42\%) were SGA and 18(64.28\%) had adverse perinatal outcome. Of the 30 out of 80 pregnancies that showed abnormal MCA PI, 21(70\%) were SGA. Abnormal cerebroplacental doppler ratio $(<1.08)$ noted in19 out of 80 pregnancies, all $19(100 \%)$ were SGA and had adverse perinatal outcome.

\section{CONCLUSION}

Cerebroplacental doppler ratio is a better pedictor of SGA fetuses and adverse perinatal outcome than the MCA PI or UA PI used alone.

\section{KEYWORDS}

Cerebroplacental Doppler Ratio, Umilical Artery Pulsatility Index, Middle Cerebral Artery Pulsatility Index.

HOW TO CITE THIS ARTICLE: Desai Sanjay D, Jyotsna A. Deshmukh. "Cerebroplacental Doppler Ratio in Evaluation of Small for Gestational age and Prediction of Adverse Perinatal outcome." Journal of Evolution of Medical and Dental Sciences 2015; Vol. 4, Issue 95, November 26; Page: 16084-16086, DOI: 10.14260/jemds/2015/2350.

\section{INTRODUCTION}

Intrauterine Growth Restriction (IUGR) is associated with adverse perinatal outcomes. The use of Doppler velocimetry has been shown to reliably predict these adverse outcomes. ${ }^{1}$ Recent studies suggest that the Cerebroplacental Doppler Ratio (CPR), which is a ratio of the pulsatility indices of the Middle Cerebral Artery (MCA) to the pulsatility indices of the umbilical artery, is a better index for predicting adverse outcomes in IUGR when compared with using either the umbilical artery Doppler values or the MCA values alone. ${ }^{2,3}$

The purpose of our study was to evaluate the usefulness of the Pulsatility Index (PI) of the Umbilical Artery (UA) and the Middle Cerebral Artery (MCA), Cerebroplacental Doppler Ratio (CPR) as the ratio of MCA PI to the UA PI in the diagnosis of Small-for-Gestational-Age (SGA), fetuses and prediction of adverse perinatal outcome. The present study was conducted to evaluate the clinically suspected cases of small for gestational age and to negative predictive value of pusatility indices and cerebroplacental Doppler ratio in predicting

Financial or Other, Competing Interest: None.

Submission 30-10-2015, Peer Review 31-10-2015,

Acceptance 06-11-2015, Published 26-11-2015.

Corresponding Author:

Desai Sanjay $D$

"Vivek" Plot No. 165, Rajopadhye Nagar,

Kolhapur-416012,

Maharashtra.

E-mail: drsanjaydesai@rediffmail.com

DOI:10.14260/jemds/2015/2350. adverse find out the sensitivity, specificity, positive pedictive value, perinatal outcome in clinically suspected cases of small for gestational age.

\section{MATERIALS AND METHODS}

The study population consisted of 80 pregnancies of 30-41 weeks' gestation had been diagnosed clinically as small for gestational age and referred for USG over a period of one year.

of the 80 cases, 40 showed normal fetal growth parameters forming the control group; 40 fetuses had abdominal circumferences less than the $10^{\text {th }}$ percentile for their respective gestational ages along with elevated Head Circumference (HC)/Abdominal Circumference (AC) ratios, formed study group.

All the 80 patients were subjected to duplex Doppler examination using $3.5-\mathrm{MHz}$ transducer. The flow velocity waveforms were recorded from umbilical artery (UA) and fetal middle cerebral artery (MCA) at proximal third. 4,5

PI of UA and fetal MCA were recorded and ratio of MCA PI to UA PI (Cerebroplacental Doppler ratio) was calculated. The pregnancies were followed-up and the final perinatal outcome of each case was noted. Various intrapartum and neonatal indicators were used to asses the outcome with an adverse outcome defined as presence of one or more of these indicators. The Cerebroplacental Doppler Ratio (CPR) remains constant in the last 10 weeks of pregnancy. 2,6 and therefore we used a single cut off value of 1.08 throughout this study where all cases were of 30-41 weeks' gestation. 
Doppler findings were considered normal when the CPR was above 1.08 and below that value velocimetry was considered abnormal. Statistical Chi square test and Fischer's test are used. $\mathrm{P}<0.05$ was considered significant.

\section{RESULTS}

The results are presented in the form of tables (Table 1-5). Of the 80 pregnancies in study, 28 showed abnormal umbilical artery PI.Among these, 20(71.42\%) were small for gestational age and $18(64.28 \%)$ had adverse perinatal outcome thirty of 80 pregnancies showed abnormal MCA PI and 21(70\%) fetuses were small for gestational age and 2(6.66\%) had adverse perinatal outcome. Perinatal death was reported in one pregnancy which showed abnormal MCA PI, abnormal UA PI and abnormal cerebroplacental Doppler ratio. Nineteen out of 80 pregnancies showed an abnormal cerebroplacental doppler ratio $(<1.08)$. Of these 19 fetuses were small for gestational age and all had an adverse perinatal outcome.

The sensitivity and negative predictive values were higher for cerebroplacental umbilical artery PI, whereas significantly lower for MCA PI.

The specificity and positive predictive value of cerebroplacental Doppler ratio and MCA PI were equal to each other, but higher than that of UA PI.

\section{DISCUSSION}

Umbilical artery and middle cerebral artery Doppler ultrasound clearly depicts the information about placental resistance and the changes in the fetal hemodynamic in response to it. Middle cerebral artery Doppler has enabled the confirmation of "Brain sparing" effect in IUGR. It is possible to use a single cut off value for cerebroplacental ratio after $30^{\text {th }}$ week because cerebral-umbilical Doppler ratio does not vary significantly between $30^{\text {th }}$ and $40^{\text {th }}$ week. ${ }^{2,6}$

The cardiovascular response to hypoxia is co-ordinated to centralize blood flow to organs such as the fetal brain, heart and adrenals. This process is well known as the brain-sparing effect. The most important adaptive reactions responsible for maintaining fetal homeostasis are probably the cardiovascular responses to hypoxia. ${ }^{7}$ Jain et al. found that the CPR ratio is a better predictor of perinatal outcome than the umbilical artery velocimetry alone. ${ }^{8}$ In general, SGA fetuses had a four-fold increased risk for adverse fetal outcome (Including hypoxic encephalopathy, intracranial haemorrhage, low Apgar score, neonatal convulsions, low umbilical pH, cerebral palsy, neurodevelopmental delay and perinatal mortality).

Unrecognized SGA fetuses had a four-fold higher risk of adverse outcome compared with those that were recognized antenatally. Furthermore, research on the long-term outcome of children born small shows higher rates of cerebral palsy and suboptimal neurodevelopmental outcome.9,10 The CPR appears to be more strongly influenced by abnormally elevated umbilical artery blood flow resistance, which may be due to the fact that placental arterial and venous blood flow changes may be interdependent affecting afterload and preload. ${ }^{11}$
In the cerebral circulation, examination of the middle cerebral artery is readily achieved at optimal insonation angles and therefore appears the preferred method in recent years.

When examining the middle cerebral artery, the sampling site has significant effects on the Doppler measurements when the PI is used. Measurements from the middle and distal thirds have significantly higher indices than those from the proximal third., ${ }^{4}$ but the proximal third appears to be less variable during changes in fetal behavioral state. 5

The sensitivity of the CPR from our study is similar to those previously reported for predicting adverse perinatal outcomes in IUGR. ${ }^{2}$

In conclusion, $\mathrm{CPR}$ should be used in prenatal monitoring of pregnancies with suspected SGA.

\section{REFERENCES}

1. Alfrevic Z, Neilson JP. Doppler ultrasonography in highrisk pregnancies: systematic review with meta-analysis. Am J Obstet Gynecol 1995;172:1379-1387.

2. Gramellini D, Folli MC, Raboni S, Vadora E, Merialdi A. Cerebral-umbilical Doppler ratio as a predictor of adverse perinatal outcome. Obstet Gynecol 1992;74:416-420.

3. Arias F. Accuracy of the middle-cerebral-to-umbilicalartery resistance index ratios in the prediction of neonatal outcome in patients at high risk for fetal and neonatal complications Am J Obstet Gynecol 1994;171:1541-1545.

4. Hsieh YY, Chang CC, Tsai HD, Tsai CH. Longitudinal survey of blood flow at three different locations in the middle cerebral artery in normal fetuses. Ultrasound Obstet Gynecol 2001;17:125-128.

5. Clerici G, Luzietti R, Cutuli A, Direnzo GC. Cerebral hemodynamics and fetal behavioral states. Ultrasound Obstet Gynecol 2002;19:340-343.

6. Waldemir off JW, Wijingaard JAGW, Dagani S, Noordam MJ, Eyck J, Tonge HM. Cerebral and umbilical arterial blood flow velocity waveforms in normal and growth retarded pregnancies. Obstet Gynaecol 1987;69:705-9.

7. Habek D, Hodek B, Herman R, Jugovic D, Cerkez Habek J, Salihagic A. Fetal biophysical profile and cerebroumbilical ratio in assesement of perinatal outcome in growth restricted fetuses. Fetal Diagn Ther 2003;18:12-6.

8. Jain M, Farooq T, Shukla RC. Doppler cerebroplacental ratio for the prediction of adverse perinatal outcome. Int J Gynaecol Obstet 2004;86:384-5.

9. Jacobsson B, Ahlin K, Francis A, Hagberg G, Hagberg H, Gardosi J. Cerebral palsy and restricted growth status at birth: population-based casecontrol study. BJOG 2008;115:1250-5.

10. Figueras F, Eixarch E, Meler E, et al. Small-for-gestationalage fetuses with normal umbilical artery Doppler have suboptimal perinatal and neurodevelopmental outcome. Eur J Obstet Gynecol Reprod Biol 2008;136:34-8.

11. Arbeille P, Maulik D, Fignon A, Stale H, Berson M, Bodard S, Locatelli A. Assessment of the fetal p02 changes by cerebral and umbilical Doppler on lamb fetuses during acute hypoxia. Ultrasound Med Biol 1995;21:861-87. 


\begin{tabular}{|c|c|c|c|}
\hline No. & $\begin{array}{c}\text { Normal PI } \\
\mathbf{n = 5 2}\end{array}$ & $\begin{array}{c}\text { Abnormal PI } \\
\mathbf{n = 2 8}\end{array}$ & P Value \\
\hline Adverse Perinatal Outcome & $3(5.8)$ & $18(64.28)$ & $<0.0001$ \\
\hline Caeserean Section for fetal distress & $6(11.5)$ & $11(39.3)$ & $<0.0001$ \\
\hline APGAR Score < 7 at 5 min & $1(1.9)$ & $8(28.57)$ & $<0.0001$ \\
\hline NICU Stay > 8 days. & $3(5.76)$ & $12(42.85)$ & $<0.0001$ \\
\hline Stillbirth/Perinatal Death & - & $1(3.57)$ & $<0.01$ \\
\hline Small for gestational Age. & $16(30.7)$ & $20(71.42)$ & $<0.0001$ \\
\hline \multicolumn{3}{|c|}{ Table 1: Perinatal Outcome in Study Group } \\
according to Umbilical Artery Pulsatility Index \\
\hline
\end{tabular}

\begin{tabular}{|c|c|c|c|}
\hline No. & $\begin{array}{c}\text { Normal PI } \\
\mathbf{n = 5 0}\end{array}$ & $\begin{array}{c}\text { Abnormal PI } \\
\mathbf{n = 3 0}\end{array}$ & P Value \\
\hline Adverse Perinatal Outcome & $19(38)$ & $2(6.66)$ & $<0.001$ \\
\hline Caeserean Section for fetal distress & $13(26)$ & $4(13.33)$ & $<0.05$ \\
\hline APGAR Score < 7 at 5 min & $8(16)$ & $1(3.33)$ & $<0.01$ \\
\hline Stay in NICU > 8 days. & $11(22)$ & $4(13.33)$ & $<0.05$ \\
\hline Stillbirth / Perinatal Death & - & $1(3.33)$ & $<0.001$ \\
\hline Small for gestational Age. & $15(30)$ & $21(70)$ & $<0.05$ \\
\hline \multicolumn{3}{|c|}{ Table 2: Perinatal Outcome in Study Group according } \\
to Middle Cerebral artery Pulsatility Index \\
\hline
\end{tabular}

\begin{tabular}{|c|c|c|c|}
\hline No. & $\begin{array}{c}\text { Normal CPR } \\
\mathbf{> 1 . 0 8} \\
\mathbf{n = 6 1}\end{array}$ & $\begin{array}{c}\text { Abnormal CPR } \\
<\mathbf{1 . 0 8} \\
\mathbf{n = 1 9}\end{array}$ & P Valve \\
\hline Adverse Perinatal Outcome & $2(3.27)$ & $19(100)$ & $<0.0001$ \\
\hline Caeserean Section for fetal distress & $2(3.27)$ & $15(78.94)$ & $<0.0001$ \\
\hline APGAR Score $<7$ at 5 min & $2(3.27)$ & $7(36.84)$ & $<0.0001$ \\
\hline Stay in NICU >8 days. & $3(4.91)$ & $12(63.15)$ & $<0.0001$ \\
\hline Stillbirth/Perinatal Death & - & $1(5.26)$ & $<0.01$ \\
\hline Small for gestational Age. & $17(27.86)$ & $19(100)$ & $<0.0001$ \\
\hline \multicolumn{2}{|c|}{ Table 3: Perinatal Outcome in Study Group according } \\
to Cerebroplocental Doppler Ratio (CPR)
\end{tabular}

\begin{tabular}{|c|c|c|c|c|c|c|c|c|}
\hline \multirow{2}{*}{$N=80$} & \multicolumn{4}{|c|}{ No. of findings } & \multirow{2}{*}{$\begin{array}{c}\text { Sensitivity } \\
\%\end{array}$} & \multirow{2}{*}{$\begin{array}{c}\text { Specificity } \\
\%\end{array}$} & \multirow{2}{*}{$\begin{array}{c}\text { PPV } \\
\%\end{array}$} & \multirow{2}{*}{$\begin{array}{c}\text { NPV } \\
\%\end{array}$} \\
\hline & TP & FN & FP & TN & & & & \\
\hline Umbilical Artery & 20 & 16 & 4 & 40 & 55.5 & 90.9 & 83.3 & 90.9 \\
\hline MCA & 21 & 15 & 0 & 44 & 58.3 & 100 & 100 & 74.5 \\
\hline $\begin{array}{l}\text { Cerebroplocental } \\
\text { Doppler ratio }\end{array}$ & 19 & 17 & 0 & 44 & 52.8 & 100 & 100 & 72.1 \\
\hline
\end{tabular}

TP-True positive FN-False Negative FP-False positive TN-True negative

\begin{tabular}{|c|c|c|c|c|c|c|c|c|}
\hline \multirow{2}{*}{$N=80$} & \multicolumn{4}{|c|}{ No. of Findings } & \multirow{2}{*}{$\begin{array}{c}\text { Sensitivity } \\
\%\end{array}$} & \multirow{2}{*}{$\begin{array}{c}\text { Specificity } \\
\%\end{array}$} & \multirow{2}{*}{$\begin{array}{c}\text { PPV } \\
\%\end{array}$} & \multirow{2}{*}{$\begin{array}{c}\text { NPV } \\
\%\end{array}$} \\
\hline & TP & FN & FP & TN & & & & \\
\hline Umbilical Artery & 18 & 3 & 3 & 56 & 85.7 & 94.9 & 85.7 & 94.9 \\
\hline MCA & 2 & 19 & 0 & 59 & 9.5 & 100 & 100 & 75.6 \\
\hline $\begin{array}{c}\text { Cerebroplocental } \\
\text { Doppler ratio }\end{array}$ & 19 & 2 & 0 & 59 & 90.4 & 100 & 100 & 96.7 \\
\hline $\begin{array}{r}T c \\
e b \boldsymbol{C}\end{array}$ & & & & & Aave & $\cdots$ & & \\
\hline
\end{tabular}

TP-True positive FN-False Negative FP-False positive TN-True negative 